Article

\title{
The Role of Techne in the Authenticity-Inauthenticity Distinction
}

Kristina Lebedeva

$\mathrm{I}$

$\mathrm{n}$ this paper I propose to do the following: I will discuss the notions of intentionality and self-understanding of Dasein as developed in Heidegger's Basic Problems of Phenomenology. In doing so, I will try to show the interrelation of Dasein's always being intentionally directed towards something and its self-interpretation. As we will see, the everyday world has, for Heidegger, a character of "equipmental contexture." This means that Dasein returns to itself from out of things, equipment, tools, or-quite differently - the work of art. In a word, Dasein is mirrored back toward itself from the things made, from the products of techne. ${ }^{1}$ From this will follow the important distinction between authenticity and inauthenticity. There is a sense in which the following pairings could be discerned: tools or pieces of equipment link up with inauthenticity, while the work of art links up with authenticity. I will say more on the subject of tools a bit later in the essay. Both kinds of things are things insofar as they are entrenched in techne. The common root seems almost inexplicable in the light of the vast difference between tools and the artwork. Moreover, both D asein and techne seem to have another equally enigmatic common root: that of temporality. Temporality is the essential bond between Dasein and the double sense of techne, which suggests the double-sidedness of temporality itself. It is precisely this doublesidedness that I would like to have as the backdrop to my discussion as a whole. Finally, I will turn to a few pages of Heidegger's Being and Time and Bernard Stiegler's book T echnics and Time I in order to complicate this notion of the two senses of temporality, the owned and disowned, originary and everyday, and its relation to work and techne. The overarching question here will be: Can the distinction between authenticity and inauthenticity be sustained?

By way of stage-setting, it is important to say a few words about the overarching theme of Section Fifteen of the Basic Problems, entitled "The fundamental problem of the multiplicity of ways of being and of the unity of

${ }^{1}$ However, we should not forget that D asein can also come back to itself from other Dasein. As Heidegger puts it, "Not only is Being towards Others an autonomous, irreducible relationship of Being: this relationship, as Being-with, is one which, with D asein's Being, already is." On another occasion, Heidegger describes being-with as "thraldom," which suggests a certain captivity and the subsequent release from it. Martin Heidegger, Being and Time (San Francisco: Harper San Francisco, 1962), 125-163. 
the concept of being in general." 2 Heidegger points out the somewhat contradictory character of modern ontology by asking: If the being of the thinking subject (res cogitans) is radically different from the being of other things (res extensa), then is it possible to say that there is such a thing as being in general? Heidegger's concern here can be understood as follows: on the one hand, he is being critical of modern ontology insofar as it understands the being of both res cogitans and res extensa as present-at-hand, which means that both have fundamentally the same way of being; on the other hand, he asks how it is possible to draw such a rigid distinction between the thinking subject and other beings and yet endorse a unitary concept of being. If the subject is indeed so different from other entities, then it must have a different mode of being. Thus, the radicalization of this very distinction between the different modes of being is called for.

In order to widen this gap between the being of the subject and the being of other beings, one needs to work out a more radical conception of the subject, which is to say that one needs to ask what D asein or human existence ${ }^{3}$ means. This is in fact what Heidegger proceeds to do in Section A by giving us the "initial preview of the existential constitution of the D asein." 4 In giving this preview, Heidegger exhibits "the being of that being to whose being (existence) an understanding of being belongs and to the interpretation of which all the problems of ontology generally return." 5 The question following out from this statement is: how does Dasein understand itself? Heidegger then asserts that Dasein is ontically ${ }^{6}$ nearest to itself because it is itself in each instance and yet ontologically furthest.7 What this important statement refers to is the difficulty of Dasein's access to itself. Although we certainly do not mistake ourselves for somebody else in our everyday commerce with the world, the "da" of D asein remains most hidden. Heidegger then says that "the D asein's comportments have an intentional character" and that "on the basis of this intentionality the subject already stands in relation to things that it itself is not." 80 ne could say then that D asein's intentionality is relational dialectic with its world.

Y et this should not lead us to believe that D asein is simply a subject because it is always characterized by intentionality, which means that perceiving is always the perception of something, thinking is always thinking of something. That is, every act of Dasein is always a relating to something and in this sense there is no interiority in $\mathrm{D}$ asein that underlies all relations. Relating belongs to

\footnotetext{
Press, 1988)

${ }^{2}$ Martin Heidegger, The Basic Problems of Phenomenology (Bloomington: Indiana University

${ }^{3}$ The G erman "da" (there) and "sein" (being) literally mean "being-there."

${ }^{4}$ Ibid., 154.

${ }^{5}$ Ibid.

6 The terms "ontic" and "ontological" describe two ways of discussing Dasein's being: the one in terms of the formal ontological structures and the other in terms of the concrete, factical way of being at any given moment. The ontic way of being is always articulated by the formal ontological structures.

${ }^{7}$ Ibid., 155.

${ }^{8}$ Ibid.
} 


\section{THE ROLE OF TECHNE}

the very ontological constitution of the subjective self. ${ }^{9} \mathrm{D}$ asein always exists in the presence of other beings and cannot therefore be isolated from them.

Heidegger further articulates precisely this point by saying that the everyday determination of Dasein as an ego is in and through this relational comportment or intentionality. ${ }^{10}$ This is not to be conflated with the idea that relational acts simply radiate from the self, that it is the given self who initiates these acts. The given ego is not the bearer of its own intentional acts because there is no given ego as such. It seems that D asein does not underlie all its relational acts but rather happens in and through them. Human existence "stands out" (the literal sense of the verb "to exist") by way of intentional acts and for that reason can never be separated from them.

Phenomenologically speaking, our dealings in the world and our understanding of ourselves as being-in-the-world are not marked by any sense of the ego. The question is then: How do we come to know and even experience ourselves as the ego? The multiple references to philosophical tradition in the chapter under consideration seem to suggest that the longestablished equation of Dasein with the isolated ego is perpetuated by the philosophical tradition itself. ${ }^{11}$ According to Heidegger, the insertion of the ego is subsequent to the event of thought. The next question Heidegger goes on to ask is: How do we experience ourselves, in what way are we given to ourselves phenomenologically? The task for Heidegger is to find an adequate interpretation of the phenomenal circumstances of Dasein, i.e., of Dasein in the facticity of its being. This means first and foremost taking into account the dictum of phenomenology, "to return to the things themselves," by freeing ourselves to the extent that we can from our conceptual presuppositions.

But what might a phenomenologically accurate account of our selfexperience be? With a view to this concern, Heidegger reaffirms that our understanding of ourselves does not arise out of a conscious discovery or thinking. As he puts it, "The self is there for the Dasein itself without reflection and without inner perception, before all reflection." $12 \mathrm{D}$ asein primarily finds itself in the things themselves it is concerned with. ${ }^{13}$ The self is neither a hidden interiority nor is it something existing in the background of all intentional acts. D asein understands itself from out of things in the world, it is always in the midst of and assailed (bedrängt) by them, which leads to what Heidegger terms the "associated unveiling of the self." 14 "In everyday terms,"

\footnotetext{
${ }^{9}$ Ibid., 157.

${ }^{10}$ Ibid., 158.

${ }^{11}$ The context of this claim is Heidegger's extensive demonstration of his thesis that the $\mathrm{G}$ reeks hastily equated being with ousia, substance. Interpreted or in effect misinterpreted in this way, being was inserted into the philosophical tradition as being present-at-hand, constant, outside of time. For details, see, for example, Section Eleven of Chapter Two in the Basic Problems of P henomenology.

12 Ibid., 159.

${ }^{13}$ Ibid.

${ }^{14}$ Ibid., 158.
} 
Heidegger continues, "we understand ourselves and our existence by way of the activities we pursue and the things we take care of." 15

Dasein's coming back to itself from out of things brings us to the important notions of authenticity (E igentlichkeit) and inauthenticity. Everyday self-understanding is not authentic insofar as it does not arise from out of "the most proper and most extreme possibilities of our own existence." 16 For Heidegger, everydayness (A ltäglichkeit) names a distinct way of existing - the one that is characterized first and foremost by pervasiveness and indifference. ${ }^{17}$ Although it is the most common way of D asein's being, the everyday D asein becomes indistinguishable from its daily concerns. The self of such understanding dissolves into things. This inauthentic self-understanding, however, is neither ungenuine nor illusory. ${ }^{18}$ It is important to realize that inauthenticity and authenticity are modes of D asein's self-understanding. The former is Dasein's interpreting itself from out of the being of those beings that are radically distinct from it or in terms of its absorbed involvement with those beings. It is also possible to say that D asein perceives itself as 'anyone,' as the anonymous 'they.' The latter is interpreting itself in terms of its most proper being or its most proper possibilities of being. The latter (which will later be referred to as the being-towards-death) is what Heidegger understands by freedom. Inauthenticity is then about absorption (A ufgehen) or, according to the literal meaning of the German term, going up into things. ${ }^{19}$ It is essentially characterized by lostness of the self. That is, our interpretative appropriation of ourselves is inauthentic or simply misguided; it is not ourselves in our most proper being that we appropriate as what we are. This does not mean that we do not have the authentic experience of ourselves in this self-absorption in things. It is rather the question of the disjunction between our experience of ourselves and our conceptual expression of it. It is this lack of a phenomenologically suitable interpretation of ourselves that Heidegger draws our attention to. ${ }^{20}$

${ }^{15}$ Ibid., 159.

${ }^{16}$ Ibid., 160.

17 "Everydayness" is the how "in accordance with which Dasein "lives unto the day ["in den Tag hineinlebt"], whether in all its ways of behaving or only in certain ones which have been prescribed by Being-with-one-another." Heidegger goes on to say that "in everydayness everything is all one and the same, but whatever the day may bring is taken as diversification." Being and Time, 370-1.

${ }^{18}$ Heidegger, The Basic Problems of P henomenology, 160.

${ }^{19}$ This is analogous to the notion of 'fallenness' (V erfallenheit) in Being and Time. Indeed, fallenness into the world means "an absorption in Being-with-one-another, in so far as the latter is guided by idle talk, curiosity, and ambiguity." Being and T ime, 175.

${ }^{20}$ One question that arises here is whether a phenomenological description of reality is more useful than its normative description. That is, there is no way to tell that someone is acting authentically or inauthentically. The difference between the two modes exists only for the one who is acting. Perhaps the indescirnibility of the two 'on the outside' has a greater philosophical significance than their invisible, private distinction. One should bear in mind, however, that Heidegger is concerned with the most general question of ontology- that of being. An inquiry into the way people appear in the social space would be a specification and therefore a deviation 


\section{6}

\section{THE ROLE OF TECHNE}

Heidegger's guiding concern here seems to be the horizon of our projection. Our understanding is, we recall, projecting ourselves upon a particular possibility of being. In the case of authentic and inauthentic existence there are two radically different horizons of projection: one is the projection upon this or that possibility as specified by one's role in life, by ontic determinations; and the other is the projection upon our existence as such, i.e., our finitude. For instance, when chooses a certain profession, it is possible to fully identify with the chosen role and do everything for its sake, that is, to succeed in one's career as if it were an end in itself. What we have in this case is the projection onto one ontic determination-one's career. This kind of projection also signifies a closure, a certain blindness to other possibilities. If, however, one realizes that the concern for his or her professional success ultimately points toward the concern for one's being as such, no full identification with this or that ontic particular will be possible. This is to say that the person in question will see him- or herself as different from the chosen object, as someone who can never be relieved of the task to choose the possibilities of one's being. In this case, the sense of difference or the space between the one who chooses and the object being chosen ensures an openness to the future, i.e., the possibility of choosing something genuinely anew.

Heidegger adds another clarification to "this mysterious reflection of the self from things" by saying that D asein is not "in" the things as something extant among them but is rather "with" the things. ${ }^{21}$ An "antecedent transposition" is the condition of our being able to return to ourselves.22 The task is to inquire into the meaning of this transposition and its relationship to the ontological constitution of D asein. The question of transposition translates into that of transcendence. ${ }^{23}$ Heidegger defines transcendence as a "fundamental determination of the ontological structure of the D asein." 24 The subject of transcendence goes hand in hand with a problem that he claims is "unknown to all previous philosophy," the problem of world. His critique of Fichte serves as a passageway to his discussion of this problem: The Fichtean dictum "Think the wall, and then think the one who thinks the wall" in effect invites us to become blind to the world. ${ }^{25}$ This is the case because the world is prior to any explicit cognitive understanding of the object.26 What is given to us is never the object

from the original inquiry. The merit of Heidegger's description is that it conceptually captures the sense of being, i.e., the way in which being affects our self-understanding.

${ }^{21}$ Heidegger, The Basic Problems of P henomenology, 161.

${ }^{22}$ Ibid.

${ }^{23}$ Ibid., 162

${ }^{24}$ Ibid.

${ }^{25}$ Ibid.

${ }^{26}$ Although I cannot discuss this in any detail due to the constraints of space and time, it should be emphasized that for Heidegger the distinction between how the world is for us and how it is in itself is not a tenable one. Given his commitment to the investigation of facticity, givenness, or the ways in which one finds him- or herself in the world, it seems that there is no passageway to any kind of supersensible realm. Otherwise put, any such realm would have to be given for Dasein in one way or another in order to fall under the scope of Heidegger's inquiry. 
in isolation. Rather, what is primarily given is a contexture, a contextual whole of equipmentality. 27 "The nearest things that surround us," Heidegger tells us, "we call equipment." 28 We see this whole from out of a practical circumspection, Umsicht. 29 What is characteristic of circumspective seeing is that it always sees things from out of our specific involvement in the world. The world that we encounter in this involved seeing is, literally, the world that surrounds us, U mwelt. This contexture is not something we can bring about or arrive at insofar as to see something as one determinate thing is to see it necessarily in relation to other things, to the whole that has already been given to us. Each piece of equipment refers to "that for which it is what it is." 30 It is thus always anchored in a specific for-which or in-order-to. ${ }^{31}$ Nonetheless, the seemingly endless chain of ends and means ultimately points back to Dasein's own being. It is D asein's own being that is first of all at stake here and that for the sake of which the referential or relational chain is activated in the first place. But yet it is precisely the "for the sake of Dasein's being" that tends to be forgotten in Dasein's dealings with the world.

Heidegger's emphasis on equipmentality may at first seem puzzling and therefore it merits a closer look. It seems that Heidegger wants to accentuate the equipmental character of things in order to disown the equation of things with mere objects, something that stands before us and leaves us indifferent. Things serve as the means to achieve our practical goals. Yet, we should not hastily conclude that the fairly simple contrast between non-useful and useful things is at stake here. The key here is that any piece of equipment is always already woven into the world and, in being used, tacitly illuminates the surrounding world to the extent it is able.

Heidegger's phenomenological interrogation of the problem of world is radical because it differs from prior philosophical inquiry. At least in modernity, philosophical inquiry into the problem of world always started from the relation between the subject and a particular isolated object. Such a formulation of the question is already a fabrication of our original experience of things in the world. Philosophy has always illegitimately redirected the problem of world to the problem of nature. ${ }^{32}$ In other words, philosophy has always sœn what was in a sense furthest from it, thus failing to recognize the concept of world as such. For Heidegger, world is neither nature nor presence-at-hand nor a totality of present-at-hand things. ${ }^{33}$ The totality of

Yet, any givenness for human experience would compromise the objective 'purity' of such a realm. What this means is that we can no longer speak of the limitation of our human faculty of understanding, for this would mean that there is a different, experientially inaccessible world that we can only speculate about. Part of Heidegger's innovation here is that he minimized the gap between the concept and life.

${ }^{27}$ Ibid., 163.

${ }^{28}$ Ibid.

${ }^{29}$ Ibid

${ }^{30}$ Ibid.

${ }^{31}$ Ibid., 164.

${ }^{32}$ Ibid., 165 .

${ }^{33}$ Ibid. 


\section{THE ROLE OF TECHNE}

things is, as he writes about it, the intraworldly, that which lies within the world. 34 This distinction is in place because for something to be an entity means that it appears within the world. Y et this does not mean that the world is the sum of what is within it. Heidegger's basic determination of world is that the "world is not something subsequent that we calculate as a result from the sum of all beings." 35 It is rather the antecedent horizon that is always ahead of us and out of which we return when we grasp this or that object. As Heidegger writes, "We are able to come up against intraworldly beings solely because, as existing beings, we are always already in a world." 36 The world, he goes on to say, has the Dasein-like mode of being. ${ }^{37}$ If the world is D asein-ish, i.e., subjective, it is precisely the phenomenon of world that calls for the radicalization of subjectivity. ${ }^{38}$

What is it that inextricably binds Dasein and the world? It is what Heidegger calls "projection" (E ntwurf). Existence is, in addition to other things, casting-forth a world. ${ }^{39}$ Since Dasein's essential characteristic was said to be an understanding of being (which is in each case mine, as we are about to see) and since Dasein and the world are essentially the same, it follows that D asein has an understanding of the world, the understanding of the world that is prior to a more nuanced understanding of this or that phenomenon in the world. ${ }^{40}$ What I would like to note here is a peculiar interlacing of an understanding of being and an understanding of the world, that is, Dasein's self-understanding and its understanding of the whole of relations. Heidegger then writes that since "world-understanding is at the same time an understandingof-itself by the Dasein," the understanding of the being that pertains to intentionality embraces two radically different ways of being, the being of D asein and that of extant or intraworldly entities. ${ }^{41}$ Such general understanding of being, Heidegger says a few lines down, is indifferent, blind to "specific ways of being." Thus, we see that intentionality in conjunction with Heidegger's "D asein-ish" concept of the world opens the way and accounts for Dasein's essential tendency to become lost in entities that are fundamentally different from it.

In the next section, Heidegger points out two essential determinations of Dasein. The first is that D asein exists for the sake of its own self or that "it is occupied with its own capacity to be." 42 The second is that Dasein is in each

\footnotetext{
${ }^{34}$ Ibid.

${ }^{35}$ Ibid.

${ }^{36}$ Ibid.

${ }^{37}$ Ibid., 166.

${ }^{38}$ Ibid., 168.

${ }^{39}$ Ibid.

${ }^{40}$ I would like to point out the essential interrelation of Dasein's understanding of its being in the world and attunement (Stimmung). This interrelation tells us that Dasein's understanding is not neutral, unspecific, or colorless. Attunement means being attuned to the world in this or that way, being disposed to one's being in the world one way or another. It is, one could say, an affective coloring that is indissoluble from D asein's understanding.

${ }^{41}$ Ibid., 175.

${ }^{42}$ Ibid., 170 .
} 
case mine (jemeinig). This "in each case mineness" (Jemeinigk eit) constitutes the singularity of $\mathrm{D}$ asein insofar as it means that $\mathrm{D}$ asein belongs to itself in its very mode of being as acting. In the "in each case" Dasein becomes plainly unmistakable to itself. Dasein's concern with its own being means that it has the task of being in this situation here and now. This task cannot be handed over to anyone else. D asein can lose or forget itself only and precisely because it is its own. ${ }^{43}$ This lostness in things is in fact the first way in which Dasein is unveiled to itself insofar as "inauthenticity belongs to the essential nature of factical D asein." 44 Heidegger states that "authenticity is only a modification but not a total obliteration of inauthenticity." 45 At this point it is possible to bring the problematic into sharper relief. On the one hand, we have the essential unavoidability of the "I," D asein's ineluctable glimpse into its "mineness" and the responsibility associated with it. On the other hand, we are told that $D$ asein is inauthentic by its very nature. Indeed, we are enigmatically told that authenticity is only a modification of D asein's purposeful comportment of the everyday. The three questions that arise here are as follows. Firstly, if D asein's reflexivity is about its coming back to itself from out of things, what kind of difference must be inscribed in the very being of things to allow for Dasein's more authentic return to itself? If directedness to things is prior to D asein's authentic self-understanding, what is it that addresses Dasein from out of things and, as it were, makes it face ontologically its ownmost being? In the crudest sense, it concerns that which sparks off change in self-understanding in the first place. The second question is this: What is it about Dasein's being that makes possible the authentic return to itself? It is thus about the "how" of change. The third question is: If the self is primarily exteriority, there seems to be no other place for D asein to return to other than the situation it is already in. Y et the focus of understanding nevertheless shifts. In what sense?46 It is about the content of change.

Given the designation of things as "intraworldly," it appears that Dasein shifts from "the world" in its richness to concrete things with a remarkable lightness. For D asein, the world tends to contract into things and grow out of them again. Heidegger substantiates such an interpretation with a reference to childhood where he says that the child's world is charged with world. ${ }^{47}$ This translates into the notion that the experience of world is prior to any experience of selfhood. The mention of childhood is followed by an appeal to Rilke's poem. Poetry or creative literature (D ichtung) is understood here as the manifestation of our being-in-the-world or something like an authentic (hermeneutically open) response to the world that addresses us from

\footnotetext{
${ }^{43}$ Ibid.

${ }^{44}$ Ibid., 171.

${ }^{45}$ Ibid.

${ }^{46}$ Although I will not address this question explicitly, I hope we will be able to see that the content of change is essentially about the way in which Dasein takes up its facticity or thrownness. Differently put, as was said before with regard to authenticity, it is about Dasein's self-interpretation.

${ }^{47}$ Ibid.
} 


\section{THE ROLE OF TECHNE}

out of things. This reference to poetry seems the presage of Heidegger's work in the 1930s marked by the explicit concern with the poetic word. One of the possible questions is: Where does poetizing end and philosophy begin if both are about letting the world speak to us? Another question we ask is: Do we need to be temporally distant from things (ruins or Rilkean walls) in order to see them in their unfamiliarity, in order to be captivated by their estranging power? If we do and if the recognition of our having-been in the world is uncanny, then is it because of our always coming too late, that is, our inability to be where we have been and even where we are now-in short, because of our mortality? Is it techne that discloses to us the fact that we as humans are necessarily unable to be at home in any moment or at any site?

Now I would to complicate matters further by shifting my discussion to Stiegler's Time and Technics. Stiegler writes, "Concern is always inscribed in a complex of tools, and a tool is always inscribed in a finality that itself stems from a mode of temporalization of temporality." 48 To bring this closer to the language of my paper, concern or care is what guides D asein through the lattice of references or relations. Even in D asein's self-forgetting, care is the singular D asein in its existing, in its multiple ways of passing through the whole of relations. A piece of equipment is lodged in the "for-the-sake-of" and hence in a kind of finality. This finality originates in a mode of temporalization of temporality, which is, Stiegler goes on to add, a forgetting. ${ }^{49}$ At this point we may wonder whether the injection of the language of temporality into D asein's transactions within the referential framework adds anything new to the already introduced notions of projection and horizons. What seems to be at stake here is the way in which Dasein endures through the everydayness and the way in which the everydayness is essentially repeatable or selfsame. Being absorbed in and permeated by its everyday concerns, Dasein acquires a certain duration, a sense of time that is selfsame, undifferentiated. The neutral, everyone's temporality is, as it were, communicated to D asein by the entities it deals with. Another way of saying this would be that D asein's disowned temporality and hence the seeming constancy of its being as such are "held together" by the things it is concerned with, not the other way around. It is this temporality that is synonymous with Dasein's forgetting of its radical singularity, its "mineness." 50

48 Bernard Stiegler, Technics and Time, 1: The Fault of Epimetheus (Stanford: Stanford University Press, 1998), 264.

${ }^{49}$ Ibid.

${ }^{50}$ For the Heidegger of Contributions to Philosophy, this will translate into the notion of E reignis, i.e., the event of appropriation or enowning. D asein becomes a self insofar as the self is given to it historically in the moment of enowning. In enowning, being determines Dasein's historical projection, which is to say, Dasein's self-understanding in terms of its own historical situation. More precisely, enowning indicates belonging-together of D asein and being. It also brings Dasein "before the passing of the last god." Here we can say that the last god, just like finitude in Being and T ime, is an indication of the experience that being is given to Dasein. It is the experience that Dasein can never be the master of its own being that, as it were, discloses being itself. See Heidegger, Contributions to Philosophy (From Enowning) (Bloomington: Indiana University Press, 2000), 286-7. 
Stiegler then asks, "But is not this forgetting of the Self salutary, referring to a more originary temporality?" I will attempt to delineate the sense in which this forgetting can be said to be salutary at all, the way Stiegler sees it.

But first a few words need to be said about the temporality of authenticity, the way Heidegger writes about it in Being and Time. It was pointed out earlier that there are two senses of horizon at work in Dasein's projection or understanding: in the first case, D asein projects itself upon particular ontic possibilities that are given to it and in the other case it understands itself from out of the possibility of its ownmost being, which is to say, its finitude. In what way can we align D asein's own being as possibility with finitude at all?

We could approach the complex and ample discussion of Dasein's being-towards-death laid out in Being and Time by first drawing two observations on what has been discussed so far in the course of present essay. First, the language of projection, antecedent horizon, and transcendence calls attention to D asein's existence as equivalent to possibility. In its being directed toward the future and coming back to itself from out of the future, the ontological realm of D asein is the realm of the possible. Y et, this realm of the possible is not infinite, for in this case Dasein would never return to itself. In other words, Dasein would glide over its possibilities without ever having to choose one or the other and without looking back to itself. Given the Daseinlike character of the world and the world as the site of disclosure of all possibilities, we can conclude that the complex of Dasein's possibilities is as finite as Dasein itself. What necessarily circumscribes the realm of Dasein's possibilities is nothing other than its own death. Second, we saw that D asein relates to its ontic possibilities by things qua tools, which means that at the level of the everydayness, D asein sees its possibilities as essentially realizable or achievable. The definitional purity of Dasein's ontic possibilities is compromised by their realizable character, their tendency to dissolve into actuality. If there is one possibility that can never be actualized, it is death. For the Heidegger of Being and Time, being-towards-death is the quintessential relation to the possible. Dasein is there as long as its death is as a possibility. He writes, "The dosest doseness which one may have in Being towards death as a possibility, is far as possible from anything actual." ${ }^{51}$ In this way, death assumes the character of the most extreme possibility, possibility in the fullest sense of the word. Heidegger then elaborates the notion of the unrealizable possibility by saying that the possibility in question is "the possibility of the impossibility of any human ex istence at all." 52 This is another way of saying that for D asein, its death can only be precisely as possible. The possibility of death, Heidegger goes on to say, "reveals itself to be such that it knows no measure at all" and "offers no support for becoming intent on something, 'picturing' to oneself the actuality which is possible." 53 Before the possibility of death, all other possibilities that are present for Dasein become unfamiliar and meaningless and for this reason

\footnotetext{
${ }^{51}$ Heidegger, Being and Time, 262.

${ }^{52}$ Ibid.

${ }^{53}$ Ibid.
} 


\section{THE ROLE OF TECHNE}

require something like a revaluation. Since this possibility also turns out to be "one's ownmost and uttermost potentiality-for-Being," it is now seen as the source of any meaningful recasting of D asein's circumstantial givenness. ${ }^{54}$ It is the openness that is first disclosed in Dasein's shattering against its finitude that allows D asein to be free, i.e., to be different from how it was before and therefore to take on its facticity in a creative, recontextualized way.

The question that emerges from this is: How does D asein's relation to its most extreme possibility affect its self-understanding? To put it in another way, what happens to D asein's self-understanding after it comes up against the limit of all of its ontic possibilities? Heidegger's discussion of guilt and the call of conscience offers us some help in answering this question. He strips the notion of guilt of its moral connotations and defines it instead as "Being-thebasis of a nullity." 55 What does it mean to say that D asein's being is grounded in the nothing, a nullity or a lack? The ground of an entity is identical with the entity's reason or cause. The groundlessness of D asein has everything to do with the fact that it is not self-caused. In other words, D asein has not been thrown into its "there" of its own accord.56 Since Dasein's facticity or thrownness is saturated with negativity, two things follow. First, its own being was, as it were, handed over to it. The event of D asein's origination always precedes it and is therefore beyond its grasp. Thus, D asein is guilty first of all to itself insofar as it constantly falls behind its own being. Second, as Heidegger tells us, Dasein is this thrown ground "only in that it projects itself upon possibilities into which it has been thrown." 57 Dasein's coincidence with its facticity, its rootedness in a particular set of circumstances and an array of particular possibilities that stems from it, is also in reference to the possibility of no-longer-existing, to the negativity of Dasein's mortal horizon which shatteringly echoes the negativity bound up with its origination. Being out for the possibility of death discloses that into which Dasein has already been thrown. Hence, Dasein's authentic relation to the future recoils upon its relation to its past insofar as in anticipating death, Dasein is free to appropriate - that is, to repeat or retrieve- what is already given to it. In a sense, D asein authentically chooses what is already its own. It comes to be ontologically itself by virtue of the individuating force of finitude. ${ }^{58}$ That is, it is with a view to its finitude that Dasein's is 'introduced' to the true nature of its cares or concerns in its world in that it realizes that its cares center around its own being.

Yet, as we saw throughout this paper, Dasein is for the most part absorbed into its everyday world of plans and concerns. It therefore seems that there must be something that pulls D asein away from its daily affairs and summons it to its groundlessness. It seems, however, that this "something"

\footnotetext{
${ }^{54}$ Ibid., 263.

${ }^{55}$ Ibid., 284.

${ }^{56}$ Ibid.

${ }^{57}$ Ibid.

${ }^{58}$ Heidegger writes that "D asein can be authentically itself only if it makes" its ownmost potentiality for being "possible for itself of its own accord." Being and Time, 263.
} 
cannot come entirely from the outside, since it is D asein's ownmost being that is at stake here. Or at least, the summons cannot be issued forth by the outside as everydayness, since it is precisely in it that the being of D asein is conflated with the being of other entities unlike it. Keeping up with the language of guilt, Heidegger terms this phenomenon "the call of conscience." What is this call like and whose call is it?

Heidegger asserts that "conscience discourses solely and constantly in the mode of keeping silent." 59 Silence is speaking insofar as it gives something to understand, but yet silence is opposed to all ontic discourse. When D asein falls under the spell of silence, it is transported into the midst of the uncanny, not-being-at-home, or, to put it another way, the unbridgeable difference between itself and everything around it, the difference between the ontological and the ontic. The call of conscience summons Dasein to its ownmost potentiality for being, which means that D asein's being becomes an issue for it in the highest degree. The call differentiates Dasein from whatever it is ordinarily involved with and it makes room for Dasein's looking at its lifecontext anew by precisely highlighting the fact that $\mathrm{D}$ asein as potentiality could have been or could yet be otherwise than it is. What this amounts to is that the call animates the possibility of a genuine change or transformation of $\mathrm{D}$ asein.

The call and the caller, Heidegger goes on to say, are paradoxically one. He writes, "The call comes from me, and yet from beyond me and over me." 60 D asein then splits into a command to authentically choose itself and the accomplishment of that command. D asein simultaneously reminds itself and is reminded that it inevitably has the task to be, that in not coming into existence of its own accord, Dasein is not quite coincident with its being and is always yet to catch up with it by assuming its having-been.

What the preceding paragraphs attempted to bring to light is the following: Dasein can appropriate its own being as that which is shot through with negativity and because of that. D asein has to pass through its own nullity in order to make an authentic choice about its being. In other words, Dasein has to allow negativity to work a change upon its self-understanding by severing it from the ontic, everyday context. Such a passage through the nothing is possible only when Dasein is called upon or addressed by something. Yet the identification of Dasein with both the call and the caller makes the situation all the more enigmatic, since we have already seen Dasein's inseparability from the world or, in other words, the blurring of interiority and exteriority. The question is then: What is the role of Dasein's everyday world when it comes to the disquieting call of conscience or the call of the nothing?

Now we are prepared to return to and assess Stiegler's claim about self-forgetting in relation to temporality and the aforesaid question. Stiegler purports to introduce the question of work into the equation of the outside with instrumentality, techne. He refers to Maurice Blanchot's example of a writer to illustrate his point. A writer is a contradiction because someone who

${ }^{59}$ Ibid., 273.

${ }^{60}$ Ibid., 275. 


\section{THE ROLE OF TECHNE}

wants to write must know that he or she possess the gift to write, yet one does not know whether the gift is in fact there, until something is written by that person. The writer is in this sense posterior to his or her work and is therefore defined by it.

Stiegler transfers the situation of the writer to that of humanity in general by saying that the "question of writing is nothing but a radicalization of that of the memory of the human." 61 Human beings recognize or, more precisely, remember themselves as having-been in the traces of writing. It is however the task of the human being to first produce these traces and in order to do that it must forget itself. To forget the self means to "let one's other be- but another who is not a self, not one's own, but quite other." 62 Disappropriation, letting go of that which is one's own is the prerequisite for work as such. Yet, the loss of the self that is quintessential for work is countered by the recognition of ourselves in the work produced, the recognition of ourselves precisely as new to or not ourselves. According to the example of the writer, the effects produced invest the person who is writing with a crucially new self-understanding.

An important point follows. If the self is somehow renewed in the process of work, there can never be attained the presence of the self. To put this in more Heideggerian language, we could say that D asein returns to itself precisely in the moment of differentiation from itself. For Stiegler, the essential intertwining and inseparability of the human being and the world is best instantiated in the phenomenon of work. In a certain sense, the notion of work brings to the fore the malleability of Dasein's self and is therefore in perfect accordance with Heidegger's decisive critique of the ego as constant presence. Work, however, is possible only on the basis of self-forgetting. The destabilization of any present or given self and the affirmation of its perpetual self-surpassing, its renewal, seems to be what motivates Stiegler's ascription of a highly positive valence to dissolution in work and the effects of work as such. What Stiegler attempts to do in making such arguments, the way I understand it, is nothing other than an intensification of Heidegger's idea that D asein's authentic self-interpretation always arises out of and cannot be separated from its inauthentic absorption in the everydayness. D asein's self-understanding is constituted in its return to itself from out of things or the effects of work, which is to say that the everyday comportment is the baseline for D asein's authentic access to itself. However, it remains unclear how Stiegler's analysis can account for any genuine change in Dasein's self-understanding. One question should suffice to show this: If, as was said earlier, the temporality of the everydayness is essentially constant and undifferentiated, if this temporality permeates Dasein's everyday absorption in techne, and, finally, if Dasein is informed by its everyday world, then where-methodologically speakingdoes the possibility of change come into the picture? The problem with Stiegler's claims then seems to be his insistence on the change-inducing value

${ }^{61}$ Stiegler, Technics and Time, 1, 264-5.

${ }^{62}$ Ibid., 265. 
of techne as such, which precludes differentiation within it. If just any instance whatsoever of techne offers a possibility of Dasein's authentic return to itself, then the phenomenon of such a renewal remains unexplained. Moreover, it appears questionable to me whether the assertion of techne in its homogeneity as well as an anonymous dispersion of D asein in the world minus the notion of "mineness" 63 (it is, after all, uncertain what exactly allows the writing person to identify with the writer brought into existence by writing) offer us the conceptual means necessary to address the transformation of experience andI am tempted to add-temporal unfolding as such. In other words, if it is the case that the analysis of temporality as such hinges upon a rigorous notion of change, the fully-developed understanding of temporality and, by extension, of historicality, the analysis that lacks such a notion does not seem to be particularly vital.

Nevertheless, the emphasis on the outside may be appreciated in the early Heidegger's own thinking of authenticity and inauthenticity. We can see that this is the case by paying attention to the troubled aspects of his notion of the call of conscience. It is not clear how we are to think about the simultaneity of D asein's calling itself and being called upon and in fact why we may want to assert the simultaneity in the first place. In other words, Heidegger- his resistance to such traditional notions of the self as interiority or self-subsisting entity notwithstanding-does not tell us why the call has to have the double origin in the world and D asein. The suspicion that thinking $\mathrm{D}$ asein as the partial origin of the call is haunted by the remnants of traditional subjectivity is fortified by Heidegger's abandonment of the language of the call of conscience altogether and the shifting of his focus to the work of art in the 1930s. Heidegger's discussions of art and the poetic word specifically could be seen as a formal explanation of how Dasein can be called upon by the world in such a way that it enables a genuine modification in Dasein's selfunderstanding. That is to say, Heidegger articulates and develops the differentiation within techne itself to allow for the possibility of change without any pronounced sense of agency. The change happens to $\mathrm{D}$ asein not because there is some hidden interiority of $\mathrm{D}$ asein that wills it, but rather because of the qualitative differences inherent in the effects of techne itself and Dasein's fundamental ability to be affected and informed by techne as it is woven into D asein's surrounding world. Heidegger thus sees that the world itself has to address Dasein in two emphatically different ways in order to say that there is more than one way of living (I use the verb in the transitive sense) temporality. The world as ordinary techne addresses D asein in a way that does not introduce it to the essential difference between the being of Dasein and that of other

\footnotetext{
${ }^{63}$ See, for instance, Stiegler's repeated references to Maurice Blanchot who, in his turn, suggests that the absorption into and the experience of language is incompatible with any discourse on subjectivity- which means that in its going out into the world, Dasein does not come up against any individuating phenomenon such as its finitude (252, 262, 264, 266 in T echnics and Time, 1). Indeed, Blanchot writes of "not proper but featureless death," death that has "no relation to me" and "no power over me" (quoted in endnote six to Part Two, Chapter Three of the Stiegler text).
} 


\section{THE ROLE OF TECHNE}

entities. The world that is calling D asein from out of the extraordinary techne of the work of art allows Dasein to return to itself in a restorative way or, differently put, to convert Dasein's circumstantial limitations into an acknowledged distinctiveness out of which something new is born. In a sense, this is exactly where Stiegler stops in his analysis: he intensifies the notion of the outside qua techne, but yet he does not elaborate on any distinction within techne that would bring about any change in D asein. I therefore find the later Heidegger's writings on art critically important in thinking through the issue of the self and the outside under the rubric of temporality without sliding into the language of interiority. To return to the question I raised at the beginning of the essay, it seems to me that the distinction between authenticity and inauthenticity- however subtle- is an integral part of Heidegger's notion of temporality as such. Whether it is possible to collapse this distinction and yet present a viable account of change is the question that remains to be critically examined elsewhere.

D epartment of Philosophy, D ePaul U niversity, U nited States

\section{References Cited}

Heidegger, Martin, Being and Time (San Francisco: Harper San Francisco, 1962). , Contributions to Philosophy (From E nowning) (Bloomington: Indiana University Press, 2000). , The Basic Problems of Phenomenology (Bloomington: Indiana University Press, 1988).

Stiegler, Bernard, Technics and Time, 1: The Fault of E pimetheus (Stanford: Stanford University Press, 1998). 